\title{
INNOVATIVE STRATEGIES FOR REINTRODUCING A SLEEPING LANGUAGE: HOW A COMMUNITY-UNIVERSITY PARTNERSHIP SUPPORTS THE REVITALIZATION OF KAURNA, THE LANGUAGE OF THE ADELAIDE PLAINS, SOUTH AUSTRALIA
}

Jack Kanya Buckskin

Kuma Kaaru and Kaurna Warra Karrpanthi (KWK)

Taylor Tipu Power-Smith

Kaurna Warra Pintyanthi (KWP) and Kaurna Warra Karrpanthi (KWK)

Jaylon Pila Newchurch

Kaurna Warra Pintyanthi (KWP) and Kaurna Warra Karrpanthi (KWK)

Tempestt Sumner-Lovett

Kaurna Warra Pintyanthi (KWP)

Paul Finlay

Kaurna Warra Pintyanthi (KWP)

Chester Schultz

Kaurna Warra Pintyanthi (KWP)

Rob Amery 1

University of Adelaide and Kaurna Warra Pintyanthi (KWP)

\begin{abstract}
A collaboration between the Kaurna community and the University of Adelaide is longstanding. This collaboration was formalised in 2002 with the establishment of Kaurna Warra Pintyanthi (KWP), a committee of Kaurna Elders, language enthusiasts, linguists, teachers and researchers. Commonwealth funding enabled KWP to establish a small part-time team in 2012 based at the University of Adelaide to support the reintroduction of the sleeping Kaurna language of the Adelaide Plains by producing resources and undertaking research. This paper shares the work of the KWP Team, which is guided by the Kaurna concept of yaityarni-apinthi "actively Indigenising," manifested through Kaurna icons on playing cards, adaptation of games, adoption of Kaurna names, developing Kaurna terms for English concepts and so on. In the absence of first-language speakers, Kaurna is reintroduced by finding niche uses for the language. In this paper we share innovative strategies used
\end{abstract}

${ }^{1}$ Correspondence: Rob Amery, University of Adelaide, rob.amery@adelaide.edu.au 
alongside long-standing practices, such as song, language classes, and immersion activities to reintroduce a sleeping language within the Kaurna community and reach out to an English-speaking audience, both Indigenous and non-Indigenous.

Keywords: language reclamation, decolonisation, Kaurna language, collaborative Language revitalization, language and electronic media

Citation: Buckskin, J. K., Power-Smith, T. T., Newchurch J. P., Sumner-Lovett, T., Finlay, P., Schultz, C., \&, Amery, R. (2021). Innovative strategies for reintroducing a sleeping language: How a community-university partnership supports the revitalization of Kaurna, the language of the Adelaide Plains, South Australia. WINHEC: International Journal of Indigenous Education Scholarship, 16(1), pp. 47-90. http://dx.doi.org/10.18357/wj1202120275. Special Issue on Indigenous Language Revitalization: Innovation, Reflection and Future Directions, Guest Co-Editors Drs. Onowa McIvor and Kari A. B. Chew. 


\section{Introduction}

A remarkable long-standing collaboration working towards the revitalization of the Kaurna language has been forged between the Kaurna community and the University of Adelaide over nearly three decades. The Indigenous co-authors of this paper are younger members of the community and were all first employed by the University of Adelaide through Kaurna language projects, dating back to 2006 in the case of Jack Kanya Buckskin, 2010 for PowerSmith, 2017 for Newchurch, and 2020 for Sumner-Lovett. These younger members of the team are being mentored in Kaurna language work and media production by Amery and Finlay as described in this paper, and in turn, serve as mentors to more recent recruits. Buckskin, Power-Smith, Newchurch, and Sumner-Lovett have taken up the challenge to carry on the Kaurna language movement with the passing or retirement of the Kaurna language pioneers: Dr Alitya Wallara Rigney, Dr Lewis Yerloburka O’Brien, Stephen Gadlabarti Goldsmith, Cherie Warrara Watkins, Ngarrpadla Josie Agius, and others.

\section{Author Introductions}

Buckskin - My Kaurna language journey commenced in 2006, following the suicide of my sister. I joined my uncle Gadlabarti's Taikurtinna Kaurna dance troupe and he encouraged me to join Kaurna language classes. Steve Gadlabarti Goldsmith was the key member of the KWP Team from its establishment in 2012 up until his untimely death in 2017. Gadlabarti was a mentor, role model and visionary. He often spoke of language enabling speakers to "hold their heads high and walk tall" and was a champion of "indigenuity" (combining Indigenous and ingenuity). 
I embraced the Kaurna language and made it my own. I wanted to be able to speak it fluently as I had heard it spoken in class. In 2008 I co-taught the Kaurna class with Amery and from 2009 taught it myself. I then taught Kaurna in schools, getting my head around different teaching styles needed. I needed fluent oral language with younger children who could not read or write. I fell in love with teaching Kaurna. In one year, I was teaching all age levels from kindergarten to adults. I was surrounded by Kaurna day and night, so by the time I had my own children, I had a good foundation. My children gave me the opportunity to use the language at home as well. I might say Ipiti-ana padni! Ninku tiyarla wirrkantu!² (Go and have a shower! Brush your teeth!). My daughter would do it, but then I'd ask her "What's the word for shower?" and she'd have no idea. It's not formal language learning. I tried to embed Kaurna in my everyday life, teaching my fellow footballers and poker players key phrases, creating opportunities for them to learn.

Power-Smith - I was tricked into working with KWP by my mother Katrina Karlapina Power who told me that they needed an extra voice to produce a radio show. It would only take a couple of hours I was told. A couple of hours turned into weeks and numerous recording sessions. Initially I was unimpressed (to say the least), but that quickly turned to gratitude once I connected with the team and started hearing language that gifted me a whole new world to explore, only this one felt like home. For me now, at 28 years of age, my vision is clearer than it has ever been. The baton has passed to me, and now it is my time to stand up for all the people that stood before me. It's my responsibility to take Kaurna language as far

\footnotetext{
${ }^{2}$ Following linguistic conventions, Kaurna words are written in italics so that they stand out in the text. The intention is to draw attention to them, notwithstanding the policy of this journal to normalise Indigenous terms.
} 
as I can. Firstly, I want to see Kaurna language mandatory in schools. I want it to become the language of the Adelaide Plains and most importantly, I want our babies to grow up speaking their mother's tongue, and I plan to dedicate my entire life to make this dream a reality.

Newchurch - I am doing a cadetship with the KWP Team whilst studying media full-time. Through the cadetship, I can gain practical experience in a range of Kaurna media production and develop my Kaurna language skills at the same time. I am being mentored by Paul Finlay, who has a wealth of experience in the industry. It is important for us, as Indigenous people, to gain these skills so that we can express ourselves and our culture on our own terms.

Sumner-Lovett - I have joined the KWP Team more recently. As an Indigenous musician and songwriter, I have found the space to express myself and give voice to my culture through song. I have now found a passion for making music centred around culture.

Finlay - I came on board as media mentor when the KWP Team was established in 2012. I work alongside the Kaurna language workers providing hands-on training in all aspects of media production, including scriptwriting, filming/recording and editing.

Schultz - I complement the KWP Team as an independent researcher. I first worked with Kaurna in 1990 contributing my expertise as a musician and composer to the songwriting workshop held in Ngarrindjeri, Narungga, and Kaurna. I have researched local music traditions in-depth. My role with KWP is focussed on historical research of Kaurna place names. I regularly attend Kaurna Warra Karrpanthi (KWK) meetings to share my expertise. 
Amery - I am the lynchpin in the relationship between the Kaurna language movement and the University of Adelaide where I am employed as a permanent academic. I have used this position to obtain Commonwealth government funding which enabled the establishment of the KWP Team and ongoing employment of Kaurna language workers. In addition to my role as manager of the project, I act as consultant linguist, teach Kaurna linguistics, and carry out ongoing research into the use and structure of the Kaurna language. My approach to research is action research, involving Kaurna people at every step of the way.

Kaurna people, employed by the University of Adelaide independent of Amery, have also played a significant role in this work. Professor Lester Irabinna Rigney, son of leading Kaurna language pioneer, the late Dr Alitya Wallara Rigney, served as the Dean and Professor of Indigenous Education from 2016 to 2017. More recently, KWK director Rod Midla O'Brien has been engaged by Wirltu Yarlu as Cultural Advisor, whilst many other members of the Kaurna community have forged their own relationships with the university through Welcome to Country performances, their role in public artwork creation, or engagement in projects of varying kinds. In their own ways they have reinforced the importance of the Kaurna language within the tertiary sector and beyond.

\section{Yaityarni-apinthi - Decolonising}

The Kaurna language movement has always had a decolonising agenda, but as a reawakening language without native speakers, Kaurna people recognise and accept the important role that linguistics plays in the reclamation of their language. As yet, there are no formally trained Kaurna linguists with postgraduate qualifications, though Buckskin for one 
now has a deep knowledge of the language and a firm grasp of many fundamental concepts in linguistics through working alongside linguists and through his own efforts to learn and teach the language.

Training, mentoring and capacity building, discussed in more detail later, are at the core of the Kaurna language movement, so that Kaurna people will continue to be in a better position to run all aspects of their language programs in future. Buckskin formulated the term yaityarni-apinthi for the decolonising process using his knowledge of Kaurna word-forming processes. Yaitya was defined by Teichelmann and Schürmann (1840) as "proper; own; native; fresh" observing the usages yaitya warra "one's own language", yaitya miyu "countryman" and yaitya kauwi "proper (i.e., fresh) water" (p. 59), (where warra is "throat; voice; speech; word; language etc", miyu "man; person" and kauwi is simply "water"). So yaitya warra is an "Indigenous language," yaitya miyu an "Indigenous person" and yaitya kauwi is "fresh water." Yaityarni-apinthi consists of four morphemes yaitya + -rni + -api + $n$ thi. The final morpheme $-n$ thi is simply the present tense marking, and its absence would mean that the action took place in the past. The second morpheme -rni is the inchoative "to become." So yaityarninthi would mean "becoming Indigenous" or "becoming proper." The additional morpheme -api is a causative "to make," invoking agency on the part of the subject of the verb. The entire word then means "making it become Indigenous or proper" or as we have translated it, "actively Indigenising." The grammatical structure of Kaurna differentiates between "Indigenising" where it is a process that just evolves, that is, yaityarninthi, versus "actively Indigenising" as a result of deliberate action, that is, yaityarniapinthi. The latter more accurately reflects the philosophy and practice of KWP and KWK. 
The two meanings of the word yaitya documented by Teichelmann and Schürmann (1840) is a fortunate happenstance with the strong implication that the Indigenous way is the proper way.

The concept of decolonisation is one that has been promoted by numerous writers including Indigenous linguist Leonard (2017) and Fitzgerald (2018). Stebbins et al. (2018) refer to a decolonising linguistics. For the Kenyan writer Ngugu wa Thiong'o, decolonisation begins with reclaiming language. ${ }^{3}$

\section{Language Reclamation}

The term language reclamation is used variously by different writers in different contexts. In South Africa, the term was used by black militant writers in the final years of apartheid to reclaim their right to speak Afrikaans with pride as their personal language and as the "language of liberation" (Van Heerden, 1991, p. 12). Afrikaans had been linked strongly with the white Afrikaaner ruling class and specifically with the hated apartheid policies prior to the African National Congress winning power in 1994. Leonard (2017) uses language reclamation as part of a decolonising strategy, stating that language reclamation is an "effort by a community to claim its right to speak a language and to set associated goals in response to community needs and perspectives" (p. 19). In Australia the term has been used in relation to sleeping or awakening languages that no longer had speakers where the language was being reclaimed or retrieved from historical records. In the Australian Indigenous Languages

\footnotetext{
${ }^{3}$ Makanaka Tuwe, "Why Decolonisation Starts With Reclaiming Language" 8 June 2018 https://www.vice.com/en nz/article/9k8zja/why-decolonisation-starts-with-reclaiming-language.
} 
Framework, language renewal was used for languages where a significant amount of vocabulary, phrases, and expressions were known and used within the community, though the language was no longer spoken fluently. The term revitalisation was used for languages where there were at least some remaining fluent speakers, though the language had diminished in its usage and efforts were needed to bring the language back into full usage. Leonard (2017), for one, uses the term reclamation for these situations where the Australian Indigenous Languages Framework (AILF) ${ }^{4}$ uses revitalisation, whereas in North America revitalization is used more broadly.

\section{The Kaurna Language of the Adelaide Plains}

Kaurna is the original language of land now occupied by the city of Adelaide, the capital of the state of South Australia, and the surrounding area called Adelaide Plains. With colonisation by England in 1836, Kaurna lands, though never ceded, were taken by the alien invaders, who were at first regarded by Kaurna people as the returned spirits of their ancestors. Europeans were referred to as pinti miyurna (men/people of the grave). Kaurna people bore the brunt of colonisation in South Australia, despite initially keeping their distance from the colonists, perhaps because of earlier activities by sealers kidnapping their women. Two colonists, James Cronk and William Williams, each went out of their way to make contact with Kaurna people, persuading several groups to visit the English encampment at Pathawilya (Glenelg). The first time Kaurna people were in a court of law, they were there as the plaintiffs when two sailors Hoare and Moon stole their belongings.

\footnotetext{
4 The national Australian Indigenous Languages Framework has enabled the introduction of accredited Aboriginal and Torres Strait Islander language programs at senior secondary level since 1994.
} 
Through the sealer Cooper, who served as their interpreter, the Kaurna men asked that the accused be let off. The newspaper article at the time (South Australian Register, 1837, p. 4) portrayed the unnamed Kaurna men in very positive terms.

The initial years of colonisation were relatively peaceful, with Kaurna leaders appointed as honorary police constables and attending regular meetings with the chief of police. However, it wasn't long before Kaurna people were pushed aside, and the relationship soured. The Kaurna population plummeted as a result of introduced diseases including smallpox, syphilis, typhoid, and influenza. Despite the establishment of a school in 1839 by German missionaries where the Kaurna language was used as the medium of instruction, the Kaurna language was silenced within three decades. It was no longer used on an everyday basis. The few remaining speakers were dispersed. The Kaurna school at Pirltawardli was closed by Governor Grey in 1845 and the children were sent to the English-only Native School Establishment. With the establishment of Poonindie Mission near Port Lincoln in 1850, Kaurna children were sent far away from their homeland to distant Barngarla lands.

With the closure of Poonindie Mission, the residents were sent to Point Pearce and Raukkan. But it wasn't until after the 1967 referendum, whereby Aboriginal people were included in the national census and the Commonwealth parliament was given the power to pass laws with respect to Indigenous Australians, when numbers of Aboriginal people were able to return to the Adelaide Plains from the Point Pearce and Raukkan missions in Narungga and Ngarrindjeri country, though some, such as the respected Kaurna Elder Auntie Gladys Elphick, were brought to Adelaide during World War II to work in munitions factories. 
Upon returning to Adelaide, some Nungas ${ }^{5}$ began re-establishing connections with their country. At first, Kaurna people were most concerned with protecting their sites, such as the freshwater springs along the coast to the south of Adelaide and making a connection through material culture. Efforts to revitalise Kaurna language and culture came later. In 1980, Kaurna-Ngarrindjeri woman Auntie Leila Rankine named Warriappendi Alternative School. Warriappendi (to seek; pick up; find) was taken from Teichelmann and Schürmann (1840, p. 54) and several Kaurna people expressed their desire to bring back the language as a spoken language in the mid-1980s. In 1989, the late Alitya Wallara Rigney obtained funding through the National Aboriginal Languages Program (NALP). Amery, a non-Aboriginal linguist, and Schultz, a non-Aboriginal musician, were recruited to work alongside local Nungas, most of whom have since passed on or have moved out of the area. In early 1990 a songwriter's workshop was held at Tandanya Aboriginal Cultural Institute in Adelaide with a focus primarily on Ngarrindjeri and Narungga songs, but at the insistence of the now deceased Kaurna Elder, Josie Agius, Kaurna was also included, these being the languages with which most local Nungas identified. Seven of the 33 songs written were in Kaurna or included some Kaurna language (see Ngarrindjeri, Narungga, and Kaurna Languages Project, 1990). This was the first time that any novel Kaurna sentences had been constructed since the language went to sleep.

\footnotetext{
${ }^{5}$ Nunga is the word for Aboriginal person used to refer to Indigenous people from southern South Australia. It is the counterpart of Koorie used in eastern Australia.
} 


\section{Kaurna Language Reclamation}

The Kaurna language has often been cited in curriculum documents both at national and state levels as a good example of a reclaimed language or of a language reclamation program (see Australian Curriculum, Assessment and Reporting Authority, 2015; Department of Education, Training and Employment, 1998; Senior Secondary Assessment Board of South Australia, 1996). Reclaiming Kaurna language means going back to the archive, retrieving whatever has been written in, on, and about the language and meticulously collating and interpreting those records to develop a workable language for use today. In the Kaurna case, there are no historical sound recordings of Kaurna speakers, so the foundation for the reclaimed language today relies solely on written sources.

\section{Kaurna Warra Pintyanthi (KWP) and Kaurna Warra Karrpanthi (KWK)}

Throughout the 1990s many requests for Kaurna names and translations were sought. Amery found himself in receipt of many of these during the course of his doctoral research. He would often consult with Kaurna Elders or provided the information and referred the requestor to seek permission from Kaurna Elders before they used it, but was seldom certain that they had actually followed through in doing so. Uncomfortable with this situation, together with Kaurna Elders Dr Lewis Yerloburka O’Brien and Dr Alitya Wallara Rigney, Amery helped form KWP in 2002 whilst at the University of South Australia. O’Brien was also based there as an Honorary Fellow. Kaurna Warra Pintyanthi was a small committee of Kaurna Elders, linguists, teachers, and Kaurna language enthusiasts that met at the university monthly to promote the Kaurna language, provide direction for Kaurna language projects, and address the numerous requests for Kaurna names and translations, now well 
in excess of 100 annually. The status of KWP is somewhat ambiguous (see Amery \& Rigney, 2007; Amery \& Buckskin, 2013). It is not an incorporated body, but neither is it a university entity. Kaurna Warra Pintyanthi's finances were initially managed by the University of South Australia and since 2004 by the University of Adelaide, though neither university has ever made any direct financial contribution to KWP. The small grassroots committee known as KWP has always maintained its independence and right to use its own branding, despite strong pressure to conform to University of Adelaide branding.

In 2013, KWK was formed as an incorporated Aboriginal organisation under the Office for Registration of Indigenous Corporations (ORIC). Kaurna Warra Karrpanthi was established as a sister organisation to KWP comprising essentially the same people. All directors of KWK are Kaurna people, though several non-Indigenous people play an important role in sharing their expertise and experience. They remain associate members without voting rights or decision-making privileges. Kaurna Warra Pintyanthi continues to be based at the University of Adelaide focussing on research and production of resources. Kaurna Warra Karrpanthi is based at Tauondi Aboriginal Community College and deals with the requests for Kaurna names, translations, and information. Kaurna Warra Karrpanthi took over the partnership with the South Australian Department for Education, which had previously been with KWP, and takes the lead in promoting the Kaurna language.

Over the years, applications were lodged to Commonwealth government funding bodies to support the work of KWP including mentoring a Kaurna language worker, writing a Kaurna learner's guide, a Kaurna dictionary project, Kaurna postcards, and so on. A number of 
Kaurna people have been employed by the University of Adelaide over the years to work on these projects. In 2012, ongoing funding was gained to employ a small team of part-time language workers at the University of Adelaide to produce Kaurna media. Whilst all members of the KWP Team are employed or engaged by the University of Adelaide, KWK maintains oversight of the project, and regular progress reports are provided at KWK meetings. This paper focusses on the work of the KWP Team.

\section{The Work of the KWP Team: Innovative Strategies for Reintroducing Kaurna}

\section{Research}

Kaurna lexicographic research and research into Kaurna grammar has been ongoing over the last three decades and underpins efforts to reclaim and reintroduce the Kaurna language. Some 20 observers in the mid- $19^{\text {th }}$ century, plus three others in the early $20^{\text {th }}$ century wrote down what they heard from the mouths of Kaurna speakers, but unfortunately made no sound recordings. Most of the wordlists are very limited in scope, and the ability of these observers to capture the sounds of Kaurna varies considerably. Apart from the very short wordlist by Black (1920), two German missionaries Clamor Schürmann and Christian Teichelmann were the most skilled and most consistent in recording the Kaurna language, and their documentation is by far the most comprehensive (Teichelmann, 1857; Teichelmann, 1858; Teichelmann \& Schürmann, 1840). They were the only observers to write a sketch grammar, and they included hundreds of phrase and sentence examples that allow further analysis of the grammar beyond their 24-page description. All in all, around 3,000 to 3,500 distinct Kaurna words were recorded in primary sources, though many of these, such as taulta (a species of fungus) or tiara (a kind of shrub) are under-defined, and 
consequently not very useful in a revived spoken language unless we go the next step and ascribe a more specific meaning to these words. Lexicographic work entails making detailed comparisons of recordings by the same observer, between different observers, and, most importantly, making comparisons with cognates from neighbouring languages. By contrast to English, the Kaurna language has three contrasting r-sounds and several t, n, and l-sounds. Teichelmann and Schürmann (1840) and other early observers seldom made the difference between these sounds explicit in their early records of the language, but they have been painstakingly analysed and reclaimed where possible.

A composite Kaurna wordlist was compiled, and numerous editions produced over the years as this wordlist was refined and expanded with the inclusion of neologisms, such as mukarntu (computer), warraityati (phone), tadlipurdi (soap) and so on. Initially Teichelmann and Schürmann's (1840) spellings were employed in all resources produced, but in 2010 a spelling reform was agreed upon at the insistence of Buckskin, the main teacher of Kaurna at the time. Rather than having to constantly check with resident linguists as to what kind of $\mathrm{r}$ or t-sound was present in a particular word, the adoption of a consistent, systematic phonemically-based spelling system allowed him and others to operate independently, once the decision was made on the best phonemic representation of the vocabulary based on the available evidence. Lexicographic work is culminating in a comprehensive Kaurna dictionary, both print-based and online to be published in 2021 .

One of the main aims of Kaurna lexicography is the pursuit of an Indigenous epistemology. The historical record is viewed through the lens of other Indigenous languages and cultures 
(see Montoya et al., 2020, p. 475). It is evident that the primary seat of emotions in Kaurna is the tangka (liver) with secondary centres in the kuntu (chest) and wingku (lungs). There are many expressions involving these organs such as tangka mampinthi (to mourn or fret) (literally, liver wavering), tangka marnirninthi (to alter the mind for the better) (literally, liver becoming good). The heart is unimportant, occurring only in the expression pulthawilta (brave; courageous) (literally, hard-hearted). See Amery (2020) for a full discussion. Embracing these Kaurna emotions allows Kaurna people to begin to feel emotions in the way that Kaurna ancestors did and break free from an English mindset. Similarly, Hinton and Ahlers (1999, pp. 63-65) describe how the Hupa people of California have drawn on traditional patterns of metonymy and metaphor in the development of new terminology.

Kaurna place names research builds on the 2007 Southern Kaurna Place Names Project, a collaboration between KWP, the South Australian Geographical Names Unit, ${ }^{6}$ Kaurna Tappa Iri, four local councils south of Adelaide, and Beanstalk Services. An interactive website (http://kaurnaplacenames.com) was established where place names are attached to precise points on a GoogleMap image and pop-up windows give brief summaries of the information. The intertwined relationship between language and culture is undisputed, and this is reflected in the motto of the project, which was formulated between senior Kaurna people and KWP (Pulthunhari payama, ngadlu yarta tampinthi - When we understand the place names, we recognise the land).

\footnotetext{
${ }^{6}$ Now under the Department of Transport \& Infrastructure.
} 
Schultz retrieves primary cultural information about the traditional named places of Kaurna language country, especially the region around Adelaide from Gawler to Fleurieu Peninsula and Encounter Bay. This project contributes to the cultural mapping of significant places whose Kaurna names were imprinted by the Dreaming. Much of the content is revisionist, often ground-breaking, sometimes controversial. Each essay seeks the original moment when someone recorded the name and place from Kaurna people still living in their traditional culture (see Schultz, n.d.).

Only a very small proportion of the original names survive, a majority are garbled, often shifted from their original place, and many are overlaid with public misinformation. In order to assemble the best available knowledge and approach their original Kaurna reality, they need multi-disciplinary research and analysis in geography, history, linguistics, anthropology, archaeology, and where possible Kaurna oral tradition. It is an ongoing workin-progress, directed especially to Aboriginal stakeholder researchers (now and in the future) who can interpret and critique the findings, both from their oral traditions and in collaboration with other specialists. Schultz continues to look for such persons (preferably Kaurna) who could learn how to continue the work in their own ways and carry it deeper into the Kaurna community. Though none has emerged so far, we believe they are coming in the new generations. 


\section{Print-Based Resources: Kaurna Learner's Guide}

Kulurdu Marni Ngathaitya (Sounds Good to Me) (Amery \& Simpson, 2013) is the Kaurna language learner's guide which sits alongside Warra Kaurna Yalaka (Kaurna Language Today) (Amery, 2017), the Kaurna vocabulary, Kaurna Alphabet Book (Buckskin et al, 2013) and Kaurna for Smarties (Gale et al, 2020). In conjunction with the Tirkanthi Kaurna (Learning Kaurna) CD and social media videos, these resources essentially provide a complete package for learning at home or as the prescribed materials for the vocational level courses.

Kulurdu Marni Ngathaitya grew out of Kaurna language courses delivered to adults over a number of years and a series of workshops with members of the Kaurna community dedicated specifically to finding suitable ways to introduce Kaurna grammar to those without a background in linguistics. The learner's guide was the culmination of years of research into aspects of Kaurna grammar. It was divided into two parts. Part A was designed to get people to use the language. It included chapters on talking with children, talking with Elders, fishing, football and so on. Part B was an attempt to explain Kaurna grammar. Participants in the Kaurna learner's guide writing workshops likened Part A to the driver's manual, whilst Part B was likened to the mechanic's handbook explaining what went on "under the bonnet."

It was important that Kulurdu Marni Ngathaitya was designed through a collaborative process involving a number of Kaurna Elders, all of whom have a profile at the beginning of the text to acknowledge their contribution and allow them to express their feelings toward 
the language, but also to ensure that Kaurna community members know who was involved in the process and that it has been fully supported by Elders since conception.

The resource is comprehensive in regard to having a plethora of example sentences and conversational style dialogues; however, the content is familiar and relatable to Kaurna community members, using topics such as football and family gatherings in the example material. Illustrations are also relatable with, for example, a Kaurna Elder providing one of her family photographs to explain Kaurna kin terms. This is in stark contrast with the majority of textbooks or print media that Kaurna people encounter on a daily basis, most of which are Eurocentric in appearance and content, reflecting the values, priorities, and selfimage of the dominant society from which many Kaurna people feel wholly or partly excluded (Smith, 2012).

\section{Print-Based Resources: Kaurna Funeral Protocols}

In 2002, workshops were held with Kaurna community members to develop resources for the conduct of funerals based on historical accounts, but also integrating contemporary practices embedded within the Christian tradition. This project resulted in a book of funeral protocols accompanied by a CD (Amery \& Rigney, 2006). It features Kaurna translations of the Lord's Prayer, well-loved hymns, and Bible verses within a liturgy in the Kaurna language that also includes what is known of traditional funerary practices such as the use of white ochre and the lighting of a fire on top of the grave. The KWP Team updated this book with revised spelling in 2020 . 
The funeral protocols book recognises that there is now a cultural and religious diversity within the Kaurna community that did not exist prior to colonisation. Most, if not all, Kaurna people can relate back to "station" or the mission that their family was sent to, leading to a new blended tradition. Even prior to the establishment of missions, missionaries, such as Teichelmann and Schürmann, were already working with Kaurna people to record vocabulary and grammar, as well as teaching Kaurna youth within a Christian-based school environment, a subvert form of colonisation in itself, albeit under the guise of natural enquiry and preservation. This resource therefore strives to blend elements of traditional Kaurna funeral practices with elements of Christianity, which will be equally familiar for many Kaurna people. The hymns and suggested Bible verses, however, have been translated into Kaurna language, in effect bridging the gap between the two sets of beliefs and essentially starting to decolonise some of the newer Eurocentric traditions, which are often underpinned by Christianity. This is an attractive entry point into the language and some of the cultural beliefs for those community members from devoutly Christian backgrounds who may feel uncomfortable engaging in cultural practices and protocols otherwise-this resource reconciles both pathways in a way which is respectful and palatable to a range of beliefs.

\section{Print-Based Resources: Song Books}

Kaurna Paltirna brings together a collection of songs which are either translated into Kaurna or are original compositions in English by community members that have then been translated into Kaurna. This resource draws maximally on the little that is known of Kaurna song traditions. Two short songlines belonging to Kaurna leaders Mullawirraburka and 
Kadlitpinna (Teichelmann \& Schürmann, 1840, p. 73) have been embellished and incorporated into song by Schultz. A CD is also included with the book to enable pronunciation and learn the melody of the original compositions. Songs and dance have always had an important role in Kaurna culture around the transmission of information including practical knowledge, history, and correct ways of living (Attwood, 2011). It therefore makes sense that the use of songs and music would be seen as a beneficial method of introducing Kaurna language to members of the Kaurna and broader community, such as the song Madlala, which talks about the different names in language for each grandparent, as well as the reciprocal relationship term for grandchildren that belongs to each. Additionally, the songs convey some of the historical experiences and figures that the younger generation in particular may not be familiar with or aware of, for example Kadlitpinna's song Pirrki Pirrki “peas," which protests against the rations distributed.

None of this information will be attainable for the majority of people through the education system or even within their own families due to the impacts of colonisation and dispossession; therefore, songs such as these also hold a significant place in cultural revitalisation, not just language revitalisation (Attwood, 2011). Many younger people, as well as adults, will sing along to the songs without even necessarily understanding the specific words, building confidence in pronunciation and aural exposure without even realising it at the time. It is now common for kindergarten children in metropolitan Adelaide to sing the Niina Marni song at their mat time at the end of the day, so it is not impossible to imagine that Kaurna language versions of nursery rhymes and other children's songs could 
become the new normal in Adelaide-based early childhood centres in the not-too-distant future.

\section{Print-Based Resources: Kaurna Playing Cards}

Recognising the role of fun and games in language learning, KWP have developed Kaurna playing cards (see Figure 1), enabling community members to participate in an everyday pastime but with the addition of iconography of influential Kaurna people, for example, Ivarrityi instead of a queen; cultural symbology, for example, murlapaka / Kaurna shield instead of hearts; and Kaurna numbers, for example, purlaityi instead of 2. Many community members will not be aware of these words and symbols. These cards will therefore prompt them to find out more, as well as instilling a sense of pride and identification with people portrayed on the cards, in contrast to the usual Eurocentric constructs, such as kings and queens, belonging to a colonial history (Smith, 2012). 


\section{Figure 1}

\section{Kaurna Playing Cards}

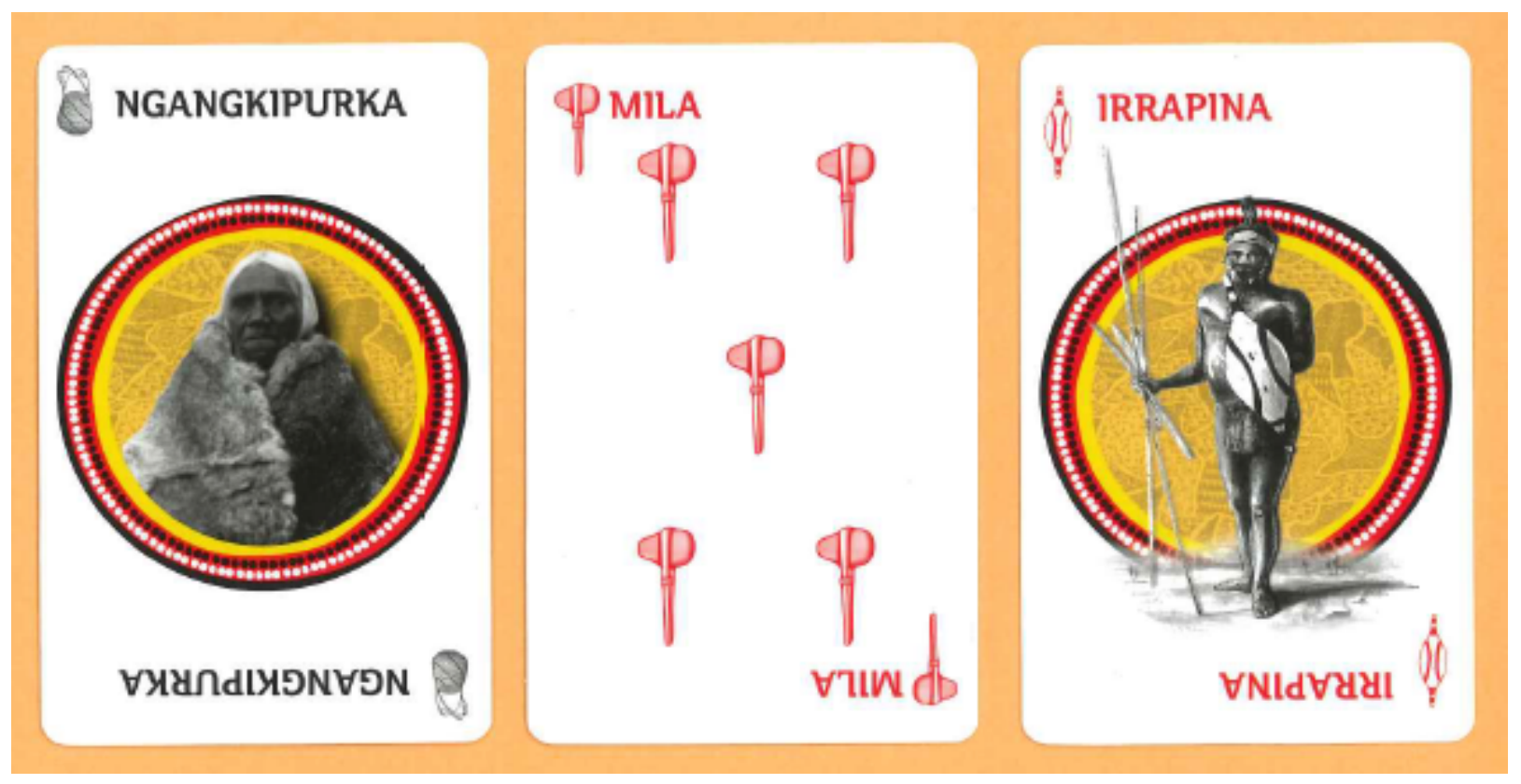

Note: Ngangkipurka (female Elder) featuring Ivarrityi (equivalent to Queen of Spades), Mila (five) Tamiaku (stone axe) (equivalent to 5 of Diamonds) and Irrapina (warrior) featuring Kadlitpinna or Captain Jack (equivalent to Jack of Hearts).

Newchurch took the lead with the production of the Kaurna playing cards, canvassing feedback on the designs and liaising with the printing firm, Print Junction, which itself is an Indigenous family business. Buckskin features as the Nikupina (joker).

The cards enable games to be played using at least some Kaurna words, whether it is by adults and the older generation playing their usual games of poker or solitaire, or the younger generation when playing memory games. Buckskin has developed a specialised Kaurna lexicon, such as purtu (full house) (from the suffix -purtu "full of") and manma- 
manmantu! (Shuffle!) (from manku-mankunthi "to make short drafts with the glass knife when sharpening or pointing a spear" involving a similar hand action), for playing poker. Cards are a gentle and informal way to start extending language use to two- or three-word phrases such as moving from saying mila (five) to waa mila? (Where's the five?) or ngai milatidli (I have a five) in keeping with the Formulaic Method (Amery, 2009). Resources such as these are also valuable for both formal and informal teaching without a significant financial investment by the purchaser, enabling numbers to be practised, leading into some basic grammar, such as the addition of suffixes for duals and plurals. The successful uptake of Kaurna cards by both Aboriginal and non-Aboriginal community has now led to exploration into how other games can be enriched with Kaurna language and will eventually lead to a Kaurna Games Book which would be useful for many settings, particularly schools and kindergartens, providing a viable alternative to activities currently practised in English.

\section{Kaurna Media}

In post-colonial Australia, English is the dominant language, and this is reflected in its almost exclusive use in media and social media (Verdon \& McLeod, 2015). Even for those who may speak another language at home, the language that will predominantly appear in social and other media is English, reinforcing that other languages will not be understood by a broader audience and therefore creating a continuing cycle of English-only use (De Bruin \& Mane, 2016; Verdon \& McLeod, 2015). By utilising a range of social media platforms such as YouTube, Instagram and Facebook, ${ }^{7}$ Kaurna Warra Pintyanthi are developing a sustained

\footnotetext{
${ }^{7}$ See the Kaurna Language Hub for the various KWP uploaded videos and playlists at https://www.youtube.com/channel/UChOOYOnJuEeydJK0QjN Fpw/featured
} 
and consistent presence that begins to normalise the appearance of Kaurna language in these spaces, an approach supported by a number of researchers, including Howell (1992) and De Bruin and Mane (2016). Videos and social media posts are easy to share and feature Kaurna community members who are known within the community, resulting in quick, cost effective, and efficient transmission of accurate spelling, grammar, and pronunciation. It is also easy to provide short, targeted lessons that prevent learners from being overwhelmed in the difficult journey of language learning, as well as providing a free resource that can be accessed at any time either alone or with family and friends. This last point is especially important as it must be recognised that Kaurna people will come to learning language from a wide spectrum of prior knowledge, and that there can be a significant degree of shame associated with their lack of knowledge or a sense that learning their own language is impossible.

Social media is not just a passive information sharing platform; it is also a public forum where people from any walk of life can share thoughts and knowledge on the topic and, in the context of language learning, can potentially create a micro-community, which can support and mentor each other in the learning journey (Ifes, 2009). This is especially important for languages such as Kaurna which are being reintroduced and have a relatively small pool of learners, let alone fluent speakers (Tsunoda, 2006). Being able to interact with each other, even if only to express pride in the video or post, can be immensely helpful in combatting isolation or frustration, as well as provide what may be the only opportunity to practise the language learned (Tsunoda, 2006). 
More evidence is becoming available around the importance of the "first 1,000 days" of a child's life, particularly in regard to how neural pathways may form during this developmental stage in response to various stimuli, including language (Guthridge et al., 2016; Jones et al., 2012). With this in mind, KWP produce the Pirltawardli puppet show aimed at preschool and primary-aged children. The puppet characters are not all fluent speakers of Kaurna. Kurraka "magpie" speaks only Kaurna. Kuula "koala" tries to speak Kaurna but often makes mistakes, creating humour. Pirlta "possum" speaks both Kaurna and English and mediates between the two. This reflects the diversity in language attainment present in the contemporary Kaurna community and importantly normalises the range of fluency present without stigma or shame. The show introduces vocabulary and has been effective in disseminating larger chunks of Kaurna language, such as nursery rhymes, to the Kaurna and broader community. Characters are all native Australian animals, reflecting the Kaurna environment, as opposed to other introduced animals, and which are therefore relatable to Kaurna children watching the show, some of whom may share a totemic name or association with the animals. Episode themes are relatable for Kaurna children, revolving around topics such as birthdays, games, and natural environmental events, albeit with a Kaurna twist, such as learning how to sing "Happy Birthday" in Kaurna language. Vocabulary in the episodes is therefore practical and more likely to be utilised and practised by children and families in their everyday lives, vital when considering the role of intergenerational transmission in language learning (Verdon \& McLeod, 2015).

Pirltawardli is frequently used as a teaching aid in primary schools, demonstrating the interest of students and willingness of teachers to integrate Kaurna language where possible, 
rather than abandoning the attempt in the face of limited availability of Kaurna language teachers. Twenty episodes are now available on the Kaurna for Kids YouTube channel.

The first Pirltawardli scripts were written by Finlay, but current scripts are written primarily by Power-Smith, whilst Power-Smith, Newchurch, and Sumner-Lovett all manipulate and speak for a puppet each. They are all engaged in filming and editing. Sumner-Lovett contributes primarily through writing and performing music and songs for the video clips. Through on-the-job mentoring all Kaurna members of the team are learning all aspects of video production. Power-Smith, who has been with the team longest, undertakes the more complex and demanding editing tasks and often directs the filming. She has also made entire video clips from start-to finish with her 11-year old daughter for the Kaurna with Tiyana series.

Recently, Friends of Pirltawardli, the brainchild of Jack Kanya Buckskin, has been developed as an offshoot of the Pirltawardli show, where Tarnta (male red kangaroo) interviews various local community members about their professions, teaching them the Kaurna words for their professions and elements associated with their jobs. Although this is another fun avenue to teach language, it is perhaps as importantly an opportunity to showcase local Aboriginal community members working in a range of areas and demonstrating to the younger generation the career pathways that can be available to them that they might not otherwise think of pursuing or consider themselves capable of. Recognising that compared to the non-Aboriginal community, there are lower levels of educational attainment, employment, and higher rates of socio-economic disadvantage within the Aboriginal 
community and that much media coverage of Aboriginal people is negative, initiatives such as this play a key role in influencing the perspectives and aspirations of young people through the provision of a positive counter-narrative (Australian Bureau of Statistics, 2010; Hartley, 1997).

\section{Kaurna Language Immersion}

In addition to physical and social media resources, it is vital to develop meaningful relationships and partnerships with community members and organisations (Ifes, 2009). Principles of self-determination, choice, and control mean that community members should be able to access both culturally specific services, as well as mainstream services, and feel that their cultural beliefs are not only respected but welcomed. Many mainstream organisations in South Australia, particularly government agencies and those with a Christian faith-based origin, often have a history of not working well with the Kaurna community, having been complicit in various detrimental and discriminatory practices and policies, such as the forced removal of Kaurna people from their traditional lands to missions, and the Stolen Generations. This has naturally developed into mistrust between community members and organisations, which requires meaningful engagement on the part of organisations, as well as a willingness to listen and adopt alternative lenses of practice and service (Ifes, 2009). By supporting mainstream organisations and programs through the provision of an advisory role, KWP is in effect contributing to the decolonisation of the broader community services system, demonstrating that it is possible to expand the scope of existing services without requiring completely new programs or significant additional funding. 
A current example is the ongoing relationship between Relationships Australia SA (RASA), Cirkidz, KWP, and Kuma Kaaru Cultural Services through the delivery of the Circus Gig program. This program is delivered in selected primary schools and works to develop improved emotional regulation, well-being and resilience through students engaging in circus skill-based activities facilitated by Cirkidz staff whilst having emotional and social well-being support through RASA staff. Although this program has been established for a number of years, the decision was made to pilot the inclusion of Kaurna language within the program, substituting frequently utilised words and phrases, such as commands, numbers and body parts, into the usual delivery of the activities. Despite partially occurring during the most severe period of Covid-19, a 6-month pilot proved successful, with the utilised social and emotional self-efficacy scale demonstrating self-reported improvements in resilience, connection to culture, and well-being outcomes. This has resulted in the current model of delivery being granted an additional 12-month funding period for another two schools and has led to further opportunities to support and guide another RASA program, Rize Above.

In May 2020, Cirkidz held a series of performances, titled Placeship, attended by school groups within the Dream Big Festival. ${ }^{8}$ Power-Smith worked intensively with the curators in forming their artistic concept to be maximally Kaurna-centric and with the performing artists tutoring them in Kaurna language. She also took a central role within the performances directing the attention and movements of the children and introducing them to Kaurna words, phrases, and expressions.

\footnotetext{
${ }^{8}$ https://www.dreambigfestival.com.au/
} 
Kaurna Warra Pintyanthi, through partnerships with KWK, is also providing Kaurna language immersion opportunities particularly, but not exclusively, targeted at those undertaking certificate level studies in Kaurna. These are combining cultural knowledge and skills, such as working with animal skins or crafting tools, with a Kaurna language-rich environment, providing additional opportunities for learners to practise not only using the vocabulary and grammar that they have learned thus far, but to practise hearing, aurally processing, and reacting to Kaurna language, an experience that very few will have the opportunity to experience outside of classes. The Kaurna language immersion activities have been led by Buckskin whilst he and other Kaurna persons have been engaged to teach the manufacture of Kaurna artefacts.

\section{Training and Mentoring}

All the way along, training and mentoring has been key to our yaityarni-apinthi philosophy. From the outset, efforts to reclaim and reintroduce Kaurna has been an active collaboration between members of the Kaurna community and linguists, researchers, and specialists in various fields with a constant aim to build capacity within the Kaurna community. Initial efforts began with a songwriting workshop in 1990, and community-focussed workshops have been a constant feature ever since, focussing variously on developing words and expressions for talking with babies and young children, Kaurna Dreamings, Kaurna place names, Kaurna welcome and acknowledgement speech-giving, artefact-making and in the writing and preparation of resources of various kinds. 
Mentoring of KWP and KWK employees has been undertaken in not only developing Kaurna language knowledge and skills, but also in a range of other skills such as scriptwriting, filming, editing, interviewing, and songwriting that are useful for language work. In 2012-2013, Mary-Anne Gale delivered an accredited Certificate III course "Learning an Endangered Aboriginal Language (Kaurna)," which she had written and delivered with a Ngarrindjeri focus a few years earlier. This was followed by a Certificate IV course "Teaching an Endangered Aboriginal Language." Our goal is to establish recognised and well-remunerated career paths for both Aboriginal language workers and teachers of Aboriginal languages and to establish a sustainable language movement.

A new Certificate III Kaurna course commenced at Tauondi College in 2019 and was taught in the evenings. In 2020, a second Certificate III Kaurna course taught during the day commenced, providing training and professional development for Aboriginal teachers and community education workers involved in Kaurna language programs in schools. There were 12 Certificate III graduates in 2020. Kaurna Warra Karrpanthi is working towards establishing its authority as the Kaurna Teachers Registration Board, such that those delivering Kaurna programs will need to register with KWK and provide information regarding their knowledge, skills, training, resources used, and links with the Kaurna community to ensure high standards and allow some measure of control by the Kaurna community over the teaching of their language. Work is still needed to ensure that the Department for Education recognises these qualifications and implements incremental remuneration tied to training outcomes. 
The importance of training, mentoring, and capacity-building is being increasingly recognised and embraced by linguists (see Czaykowska-Higgins, 2009; Fitzgerald, 2018; Poetsch et al., 2019; Stebbins et al., 2018). The divide between linguists and community is becoming increasingly blurred with numbers of Indigenous people, such as Wesley Leonard, gaining formal qualifications in linguistics and with linguists engaged in long-term collaborations with community such that the two are learning from each other (Leonard \& Haynes, 2010).

\section{Discussion}

The term "reclamation" in the context of the Kaurna language movement refers to more than the linguistic aspect of reinstating the language from a sleeping or dormant state. It also refers to taking the language back from the colonial gaze, of being viewed as an object to preserve as a historical curiosity in the face of determined and deliberate attempts to eradicate language and culture (Smith, 2012). Furthermore, it refers to returning control of the language back to the Kaurna community, who for so long had their inherent rights to speak their own language denied through both deliberate governmental practices and the casual racism of dominant society (Smith, 2015). Younger members of the Kaurna community are now feeling a sense of pride in being able to master their own language, from being able to speak it openly and proudly at large events through the provision of Welcome to Country, to being able to look in their cupboard at home and name everyday items in both Kaurna and English. It is now being seen as a distinct possibility that future generations of the Kaurna community will be able to grow up knowing their own language as a matter of 
course, rather than having to come to it in their later years with the knowledge that they are the next in a line of generations which have been denied that right.

Yaityarni-apinthi is the foundation for all the resources and partnerships that have been discussed. Reintroducing Kaurna language to the Kaurna and broader community has become more than simply a language movement, it has become a broader decolonisation movement which has been built from the grass roots with a largely volunteer base. Due to the extremely limited number of speakers and the fact that the revitalisation still has a long way to go, even the loss of one key person has a hugely disproportionate effect; however, those still involved continue to keep the course through their love for the language and respect for those who have come before. Despite the loss of several prominent leaders over recent years, the younger generation is gaining skills and has maintained momentum.

Avenues are being explored to ensure the Kaurna language is accessible and relevant for this and future generations. This includes considering how to best integrate technology to improve access and opportunities for current and future learners, as well as capacity building and training for current and emerging leaders. The demand for Kaurna language teachers continues to increase as more people in the Kaurna and broader community become aware of the language, leading to demand outstripping supply.

Despite the high demand for teaching and resources, the impetus remains to ensure that the concept of yaityarni-apinthi is not lost in the chaos. There is a temptation to rush the development of resources to meet requests and provide a simplified version of the language 
to enable ease of learning or access, particularly when requests for translations are received. Although the language needs to evolve to incorporate new concepts and vocabulary if it is to one day become an everyday language again, the timing and thought processes should not be necessarily those that are convenient to the dominant society and its expectations. This often requires more effort around relationship building and dialogue; however, the rewards of challenging the dominant status quo and providing education around Kaurna ways of thinking and history are generally worth the additional effort.

\section{Conclusion}

Undoubtedly, some truly innovative resources have been developed over the years, and will continue to be developed, particularly as momentum increases around increasing access to Kaurna language in schools and pre-schools. Although the reclamation of Kaurna language, in both senses of the term, initially relied heavily on the evidence left by non-Aboriginal recorders, as well as the interpretation and analysis by non-Aboriginal linguists, the leadership and control of the movement is now firmly in the hands of the Kaurna community. There will likely always be a need for a strong, respectful relationship between the Kaurna community and non-Aboriginal specialists, such as linguists; however, the ideological inspiration and practical realisation of the movement, including the distribution of resources, are occurring under Kaurna direction. Kaurna Warra Karrpanthi meetings involve everyone, but only Kaurna people have the right to make decisions and all non-Indigenous associate members are fully supportive of this. Public lectures, conference presentations, and academic papers are often co-presented and co-written by Kaurna and non-Indigenous team 
members, providing complementary knowledge and perspectives. The composite is more than the sum of its parts.

With the planned next steps, it is only a matter of time before the oversight of Kaurna language teaching is in Kaurna hands, as well as the majority of the teaching. Although the movement is still fragile due to the small number of speakers, the movement has already had a significant impact on not only its own community, but on other Aboriginal communities across Australia as they seek to support or reintroduce their own languages. There is immense resolve and passion within the language movement leadership and the Kaurna community alongside an excitement for future developments. 


\section{Glossary}

gadlabarti [kardlaparti] native bee

ipiti-ana padni! go to the shower!

irrapina warrior

Ivarrityi [iparrityi] (lit. misty rain) - name of 'last speaker' of Kaurna known to authorities in Adelaide as Princess Amelia.

Kadlitpinna [kadlitpina] (lit. father of dingo) - name of Kaurna leader known to the colonists as Captain Jack

kanya rock

karlapina lover of fire

Kaurna name of the language of the Adelaide Plains, South Australia

Kaurna paltirna Kaurna songs

Kaurna Tappa Iri [Kaurna Tapa Irdi] - name of the partnership agreement between the Kaurna and four southern councils (local governments)

Kaurna Warra Karrpanthi (KWK) (lit. supporting Kaurna language) - name of the incorporated Kaurna language body established in 2013

Kaurna Warra Pintyanthi (KWP) (lit. creating Kaurna language) - name of the Kaurna language committee formed in 2002

kauwi water

kulurdu marni ngathaitya sounds good to me

Kuma Kaaru (lit. one blood) - name of Jack Kanya Buckskin's dance troupe

kuntu chest

kurraka magpie 
kuula koala

madlala grandfather (father's father)

manku-mankunthi to make short drafts with the glass knife when sharpening or pointing a spear

manma-manmantu! shuffle!

midla woomera or spearthrower

mila five

miyu man; person

mukarntu computer

murlapaka dry bark shield

Murlawirraburka [murlawirrapurka] (lit. old man of the dry forest) - name of Kaurna leader known to the colonists as King John.

Narungga name of the language of Yorke Peninsula, South Australia

ngai milatidli I have a five

ngangkipurka female Elder

ngarrpadla auntie

Ngarrindjeri name of the language of the Lower Murray River, South Australia

niina marni? are you good?

nikupina joker

ninku tiyarla wirrkantu! brush your teeth!

Nunga Aboriginal person from southern South Australia

Pathawilya (lit. swamp gum foliage) - Kaurna name for Glenelg/Holdfast Bay pila a species of eagle 
pinti miyurna Europeans

pirlta brushtail possum

pirltawardli possum home - Kaurna name of the site of the Native Location, Adelaide

pirrkipirrki peas

pulthawilta brave

pulthunhari payama, ngadlu yarta tampinthi when we understand the place names we recognise the land

purlaityi two

purtu full

tadlipurdi soap

taikurtinna [taikurtirna] family

tamiaku axe

Tandanya [tarntanya] (lit. male red kangaroo rock) - national Aboriginal Cultural Institute, Adelaide

tangka liver

tangka mampinthi to mourn or fret

tangka marnirninthi to alter the mind for the better

tarnta male red kangaroo

tipu spark

tirkanthi Kaurna learning Kaurna

waa mila? where is the five?

walara clear-headed; intelligent

warra throat; voice; speech; language; word 
warra Kaurna yalaka Kaurna language today

warraityati telephone

warrarra healer

Warriappendi [warri-apinthi] (lit. to seek; pick up; find) - name of a school in Adelaide

wingku lungs

Wirangu name of an Aboriginal language from the west coast of South Australia

Wirltu Yarlu (lit. sea eagle) - name of the Indigenous programs unit, University of Adelaide yaitya Indigenous

yaityarni-apinthi actively Indigenising

yerloburka [yarlupurka] old man of the sea 


\section{About the Authors}

Jack Kanya Buckskin is a Kaurna, Narungga, and Wirangu man, born in Adelaide, who has dedicated himself to learning and sharing Kaurna language and culture. He has been involved in the Kaurna revitalisation movement for 15 years and continues to contribute to the development and teaching of Kaurna language and culture.

Taylor Tipu Power-Smith is a Kaurna and Narungga mother of two. She comes from a line of powerful and inspiring women and is passionate about language and culture. After learning Kaurna in 2012, Taylor went on to teach it for a number of years. She's now part of a media team that works to create and produce Kaurna resources.

Jaylon Pila Newchurch, as a young Narungga and Kaurna man, took Kaurna classes in his secondary years at school with Jack Kanya Buckskin. Since then, Pila has worked with Tauondi College and the KWP Team and is now studying a bachelor's in media at the University of Adelaide, concurrently placed with the KWP Team on a cadetship.

Tempestt Sumner-Lovett is a 29-year-old Aboriginal Australian Musician from the Ngarrindjeri Nation. Tempestt first began their career in music with their family band as a back-up singer travelling across the country and partly across the globe. Tempestt is mostly known as a solo artist writing their own music and lyrics and performing at various venues and festivals across Adelaide. They are currently a part-time trainee at KWP.

Paul Finlay has worked as a freelance camera operator, director, editor, and producer on a variety of film and TV productions for over 40 years. He was head of educational technology at the University of Adelaide for 8 years in the 1980s. In 2005 he was appointed SA state manager of the Australian Film Television and Radio School, (AFTRS) until 2011. He is currently working as a media production mentor for Kaurna Warra Pintyanthi at the University of Adelaide.

Chester Schultz is a composer, pianist, BA Honours history. He has worked with Aboriginal cultural revivals around Adelaide for nearly 50 years: with the Centre for Aboriginal Studies in Music since 1973, and with Kaurna, Narungga, and Ngarrindjeri language groups since 1990. His publications include Our Place, Our Music and KWP's songbook Kaurna Paltinna.

Rob Amery is head of linguistics, University of Adelaide. Rob completed a PhD in 1998 (published 2000; 2016) on Kaurna language reclamation. For more than 30 years he has worked closely with Kaurna people and their language, drawing on earlier experience in Central Australia and Arnhemland to develop teaching programs, produce language resources, and implement strategies to reintroduce the awakening Kaurna language. rob.amery@adelaide.edu.au

Acknowledgements: This work is supported by the Australian Commonwealth Government Indigenous Language and Arts program Grant no. ILAD00007 and by the Australian Research Council Grant no. DP190102413 “Towards Sustainable Language Revival: A critical analysis of Kaurna." Thanks also to Claire Fleckner for her assistance in the preparation of this paper. 


\section{References}

Attwood, B. (2011). Aboriginal history, minority histories and historical wounds: The postcolonial condition, historical knowledge and the public life of history in Australia. Postcolonial Studies, 14(2), 171-186.

Australian Bureau of Statistics. (2010). The health and welfare of Australia's Aboriginal and Torres Strait Islander peoples (ABS Article No. 4704.0). https://www.abs.gov.au/AUSSTATS/abs@.nsf/lookup/4704.0Chapter3600ct+2010

Australian Curriculum, Assessment and Reporting Authority. (2015). Australian curriculum: Framework for Aboriginal languages and Torres Strait Islander languages - Structure. https://www.australiancurriculum.edu.au/f-10curriculum/languages/framework-for-aboriginal-languages-and-torres-straitislander-languages/structure/

Amery, R. (2009). Kaurna language reclamation and the formulaic method. In W. Y. Leonard \& Stelómethet E. B. Gardner (Eds.) Language is life. Proceedings of the $11^{\text {th }}$ annual Stabilizing Indigenous languages conference June 10-13, 2004 at University of California at Berkeley. Report 14, Survey of California and other Indian Languages. pp. 81-99). http://linguistics.berkeley.edu/ survey/resources/publications.php

Amery, R. (2016). Warraparna Kaurna! Reclaiming an Australian language. University of Adelaide Press.

Amery, R. (2017). Warra Kaurna Yalaka, Warra Kaurna Pukinangku. Kaurna language today, Kaurna language from long ago. Kaurna Warra Pintyanthi.

Amery, R. (2020). Emotion metaphors in an awakening language: Kaurna, the language of the Adelaide Plains. Emotion, body and mind across a continent: Figurative representations of emotions in Australian Aboriginal languages. Special Issue of Pragmatics and Cognition, 27(1). 273-313.

Amery, R. \& Buckskin, J. (2013, October 1-4). Having it both ways: Towards recognition of the Kaurna language movement within the community and within the university sector. Proceedings of FEL XVII endangered languages beyond boundaries: Community connections, collaborative approaches, and cross-disciplinary research. The 17th Conference of the Foundation for Endangered Languages, Ottawa, ON, Canada.

Amery, R. \& Rigney, W. A. (2006). Kaurna Palti Wonga - Kaurna Funeral Protocols. Kaurna Warra Pintyand

Amery, R. \& Rigney, A. (2007, October 26-28) Collaborative language revival - the work of Kaurna Warra Pintyandi (Adelaide Plains, South Australia). Proceedings of FEL XI working together for endangered languages: Research challenges and social impacts. 
The $11^{\text {th }}$ Conference of the Foundation for Endangered Languages, Kuala Lumpur, Malaysia. (pp. 21-28).

Amery, R. \& Simpson, J. (2013). Kulurdu Marni Ngathaitya! Sounds good to me! A Kaurna learner's guide. Wakefield Press.

Czaykowska-Higgins, E. (2009). Research models, community engagement, and linguistic fieldwork: Reflections on working within Canadian Indigenous communities. Language Documentation and Conservation, 3(1), 15-50. http://hdl.handle.net/10125/4423

De Bruin, J., \& Mane, J. (2016). Decolonising ourselves: Language learning and Maori media. Critical Arts, 30(6), 770-787.

Department of Education, Training and Employment. (1998). Warranna Purruttiappendi reviving languages - living languages: Renewal and reclamation programs for indigenous languages in schools.

Fitzgerald, C. (2018). Reflections on language community training. In McDonnell, B., BerezKroeker, A., \& Holton, G. (Eds.) Reflections on Language Documentation 20 Years after Himmelmann 1998. LD\&C Special Publication 15, 86-99. http://hdl.handle.net/10125/24811

Guthridge, S., Li, L., Silburn, S., Qin Li, S., McKenzie, J., \& Lynch, J. (2016). Early influences on developmental outcomes among children, at age 5, in Australia's Northern Territory. Early Childhood Research Quarterly, 35, 124-134.

Hartley, J. (1997). An Aboriginal public sphere in the era of media citizenship. Culture and Policy, 8(2), 43-65.

Hinton, L. \& Ahlers, J. (1999) The issue of "authenticity" in California language restoration. American Anthropological Association, 30(1), 56-67.

Howell, W. (1992). Minority-language broadcasting and the continuation of Celtic culture in Wales and Ireland. In S.H. Riggins (Ed.), Ethnic minority media: An international perspective (pp. 217-242). Sage.

Ifes, J. (2009). Human rights from below: Achieving rights through community development. Cambridge University Press.

Jones, C., Meakins, F., \& Muawiyath, S. (2012). Learning vowel categories from maternal speech in Gurindji Kriol. Language Learning, 62, 1052-1080.

Leonard, W. Y. (2017). Producing language reclamation by recolonizing "language." Language Documentation and Description, 14, 15-36. 
Leonard, W. Y., \& Haynes, E. (2010). Making “collaboration" collaborative. An examination of perspectives that frame linguistic field research. Language Documentation and Conservation, 4, 268-293.

Montoya, I. L., Harry, D., \& Burns, J. (2020). A collaborative development of workshops for teachers of Great Basin languages using principles of decolonization and language reclamation. Language Documentation and Conservation, 14, 462-485.

Poetsch, S., Jarrett, M., \& Angelo, D. (2019). Learning and teaching Gumbaynggirr through story: Behind the scenes of professional learning workshops for teachers of an Aboriginal language. Language Documentation and Conservation, 13, 231-252.

Schultz. C. (n.d.). Online essays of Kaurna placenames. Kaurna Warra Pintyanthi. https://www.adelaide.edu.au/kwp/placenames/research-publ/

Senior Secondary Assessment Board of South Australia. (1996). Australian Indigenous languages framework.

Smith, L.T. (2012). Decolonizing methodologies: Research and Indigenous Peoples (2 ${ }^{\text {nd }}$ ed). Zed Books.

Smith, L.T. (2015). Imagining our own approaches. Cataloging \& Classification Quarterly, 53, 473-474.

South Australian Register (1837, July 8).

https://trove.nla.gov.au/newspaper/page/2052348?

Stebbins, T. N., Eira, K., \& Couzens, V.L. (2018). Living languages and new approaches to language revitalisation research. Routledge.

Teichelmann, C. G. (1857). Dictionary of the Adelaide dialect. MS 4vo. pp. 99 (with double columns). No. 59, Bleek's Catalogue of Sir George Grey's Library dealing with Australian languages, South African Public Library.

Teichelmann, C. G. (1858). Of the verb. MS 8vo. pp. 3. No. 57, Bleek's Catalogue of Sir George Grey's Library dealing with Australian languages, South African Public Library.

Teichelmann, C. G. \& Schürmann, C. W. (1840). Outlines of a grammar, vocabulary, and phraseology, of the Aboriginal language of South Australia, spoken by the natives in and for some distance around Adelaide. Adelaide. Authors.

Tsunoda, T. (2006). Language endangerment and language revitalisation: An introduction. Mouton de Gruyter.

Van Heerden, E. (1991). Reclaiming language. Iowa Review, 21(2), 9-14. 
Verdon, S., \& McLeod, S. (2015). Indigenous language learning and maintenance among young Australian Aboriginal and Torres Strait Islander children. International Journal of Early Childhood, 47(1), 153-170. 